cess and in laboratory practice for diagnostic and control of the elimination program could be achieved only on the basis of following guidelines mentioned in article 21 "Transnational practices", which facilitate the exchange of new technologies and Article 23 "Education, training and information in the field of bioethics" which give the universal orientation for ethical cooperation.

1.11

doi: 10.15789/2220-7619-2018-4-1.11

EPIDEMIOLOGICAL CHARACTERISTICS, ETIOLOGICAL STRUCTURE AND MODERN METHODS OF DETECTION OF PATHOGENS OF ACUTE INTESTINAL VIRAL INFECTIONS IN ORGANIZED GROUPS

V.V. Malyshev, D.V. Razumova

S.M. Kirov Military Medical Academy, St. Petersburg, Russia

In organized collectives of the Armed forces of the Russian Federation, acute intestinal infections (AII) occupy one of the leading rank places, which is associated with the level of morbidity and with large labor losses. Diagnostics is carried out taking into account the requirements of documents of the Sanitary legislation of the Russian Federation, using modern methods of laboratory diagnostics. Recently, specific laboratory studies indicate the dominance in the etiological structure of acute intestinal viral infections of unknown etiology (AIVIUE) of intestinal viruses, the most significant of which are viruses that cause enteritis and gastroenteritis: rotaviruses, caliciviruses, including noroviruses and related viruses, astroviruses, adenoviruses, enteroviruses, etc. Special place is occupied by the group incidence of acute intestinal viral infections (AIVI). In recent years, for these purposes are embedded devices, styling, diagnosticums and test systems made in Russia, some of them are tested in the army now.

The aim of the work was to assess the epidemiological significance of AIVI in military personnel, the etiological structure of viruses and diagnostic value, means of sample preparation and their detection. Detection of markers of rotaviruses, adenoviruses and noroviruses in feces was carried out by methods of enzyme immunoassay (ELISA), real-time PCR with multiplex test system "OKA-screen", in addition, the method of latex agglutination using domestic test systems "Rota-screen, "Adeno-screen", "Noro-screen" was used. Enteroviruses (ECHO, Coxsackie A, Coxsackie) was determined in the feces of a classical virological method of neutralization. It is established that a leading place among the causative agents of viral etiology OKA occupied: rotaviruses $-49 \%$, noroviruses $12 \%$, adenoviruses $-9 \%$, astroviruses $-1 \%$, enteroviruses $(\mathrm{ECHO}-18 \%$, Coxsackie A $8 \%$, Coxsackie B $-3 \%)-29 \%$.

Thus, complete etiological decoding of AIVI with the help of specific laboratory tests allows to evaluate both epidemiological and clinical features of acute intestinal viral infections in organized groups.

\subsection{2 doi: 10.15789/2220-7619-2018-4-1.12 \\ COMPLIANCE OF HEALTH CARE WORKERS WITH VACCINATION AS THE FACTOR OF FORMATION OF POSITIVE ATTITUDE TOWARDS VACCINATION IN THE POPULATION}

T.A. Platonova ${ }^{1}$, E.S. Koltunova ${ }^{2}$, O.Yu. Olshvang ${ }^{1}$, A.A. Golubkova ${ }^{1}$

${ }^{1}$ Ural State Medical University, Yekaterinburg, Russia $;{ }^{2}$ Children's City Clinical Hospital No. 11, Yekaterinburg, Russia

Despite the importance of preventive vaccination to eradicate infectious diseases, in recent years, there were those who doubt about the need to continue mass immunization.
The aim of the study is to evaluate the role of health care workers in shaping the attitude towards vaccination among the population.

In the research, an anonymous questionnaire was designed and 865 parents were surveyed about their attitude towards vaccination. $78.2 \%$ of respondents believe that vaccination is necessary, $6.7 \%$ are convinced that vaccination is not needed, and $15.1 \%$ did not answer the question about the advisability of vaccination.

When assessing the attitude towards vaccination among people of different age and education level, no significant differences have been revealed $(\phi<1.64, \mathrm{p}>0.05)$. When analyzing the gender structure of the respondents, the most reluctant parents were found among men $(\phi>2.31$, $\mathrm{p}<0.01$ ).

A negative attitude to vaccination among parents was linked with the uncertainty of their safety $(45.2 \%)$. In the second place, it was observed that the vaccinated children could also get sick $(16.0 \%)$ and then there were doubts about the quality of modern vaccines $(11.5 \%)$.

The majority of parents $(76.8 \%)$ stated that they often received information about vaccinations from health care professionals and less often from relatives, friends, Internet, and television $(\phi>2.31, \mathrm{p}<0.01)$.

To assess the opinion of health care workers about vaccination, a survey of 1325 employees of five various hospitals was conducted. It has been established that the majority $(85.9 \%)$ had a positive attitude towards vaccination, and $4.5 \%$ were negative and $9.6 \%$ were unable to formulate their answer.

Among 187 employees who do not trust the vaccination there were 41 physicians, 79 nurses, 14 paramedical personnel and 53 employees of non-medical specialties. Among physicians of different specialties the greatest number of opposed employees were among dentists, surgeons, pediatricians, intensive care workers and laboratory workers. A negative attitude towards vaccination was most often found among employees with work experience over 20 years $(\phi>2.31, \mathrm{p}<0.01)$, while no significant gender differences were revealed $(\phi<1.64, \mathrm{p}>0.05)$.

Thus, to improve the system of preventive vaccination, it is necessary to raise the awareness of health care professionals in matters of vaccination, because they are the most important and authoritative sources of information about vaccination for the population.

\subsection{3 doi: 10.15789/2220-7619-2018-4-1.13 \\ CLINICAL-EPIDEMIOLOGICAL CHARACTERISTIC OF THE INFLAMMATORY BOWEL DISEASES IN SAINT PETERSBURG}

D.S. Purgina ${ }^{1}$, L.V. Lyalina ${ }^{1,2}$, V.V. Rassohin ${ }^{1,3}$

${ }^{1}$ St. Petersburg Pasteur Institute, St. Petersburg, Russia $;{ }^{2}$ NorthWestern State Medical University named after I.I. Mechnikov, St. Petersburg, Russia $;{ }^{3}$ Pavlov First St. Petersburg State Medical University, St. Petersburg, Russia

One of the leading problems in the structure of diseases of the digestive system are the Inflammatory bowel disease (IBD), which includes the Ulcerative colitis (UC) and the Crohn's disease (CD). In recent years, a steady increase in the incidence of UC and CD has been noted in industrialized countries. The peak incidence falls on the age of 15-35 years. The aim of our research was to study the incidence and prevalence of the UC and CD among adults, and also to analyze the sex and the age features of their course in Saint Petersburg. We evaluated the incidence of UC and CD among adults in two districts (Frunzensky and Vyborgsky) in Saint Petersburg 
in 2017. The total number of patients with IBD was 459 people. The results of the research showed that the incidence of UC and CD is higher in the Vyborgsky district than in the Frunzensky district $(\mathrm{p}<0.05)$, the prevalence is almost the same in both regions $(p<0.05)$. The incidence of UC is 9.05 per 100000 people in the Frunzensky district in 2017, in Vyborgsky it is 12.58 per 100000 people. The incidence of CD is 3.21 per 100000 people in the Frunzensky district in 2017, in Vyborgsky it is 6.29 per 100000 people. The prevalence of UC is 40.6 per 100000 people in the Frunzensky district in 2017, in Vyborgsky district it is 38.9 per 100000 of the population. The prevalence of the CD is 20.4 per 100000 population in the Frunzensky district, in Vyborgsky district 23.9 per 100000 population. Among patients with UC, women predominate in a ratio of $1: 2(p<0.05), C D$ is almost the same in men and women $(p<0.05)$. The incidence of UC prevails over the incidence of $C D$, as well as higher incidence rates among female patients $(\mathrm{p}<0.05)$. An analysis of the age structure showed that about $50 \%$ of cases of UC occur at the age of 20-49 years, about $40 \%$ of patients with UC are in the age group over 60 years, no more than $10 \%$ of cases occur at the age of $18-19$ and $50 \% 59$ years old. More than $60 \%$ of patients with $\mathrm{CD}$ are in the age group of $20-49$ years and about $25 \%$ of cases of $\mathrm{CD}$ are in patients older than 60 years, about $15 \%$ in the group of 50-59 years and no more than $5 \%$ of cases in the 18-19 age group. Given that the incidence of $\mathrm{UC}$ and $\mathrm{CD}$ are higher among women and more than $50 \%$ of patients are in the most able-bodied age of 20 49 years, inflammatory bowel disease is a group of highly relevant and socially significant diseases. The revealed differences in morbidity between districts should be taken into account when organizing preventive, therapeutic and diagnostic activities.

1.14

doi: 10.15789/2220-7619-2018-4-1.14

\section{THE USE OF CORRELATION ANALYSIS ON THE EXAMPLE OF INFLUENZA VACCINATION ON THE TERRITORY OF THE ROSTOV REGION}

S.S. Slis', E.V. Kovalev, S.A. Nenadskaya,

G.A. Miroshnichenko

Rostov Region Surveillance Directory, Rostov-on-Don, Russia

Vaccination company is held every year in Rostov region before the epidemic increase of influenza infection. For immunization, influenza vaccines of domestic and foreign production are used, included for the Northern hemisphere on the recommendation of the world health organization of actual strains of influenza $\mathrm{A}(\mathrm{H} 1 \mathrm{~N} 1)$, $\mathrm{A}(\mathrm{H} 3 \mathrm{~N} 2)$ and $\mathrm{B}$ for the current season.

To assess the vaccination effect in the Rostov region, sings of influenza infection were analyzed during the epidemic seasons and coverage of preventive vaccinations during the 15 seasons (season 2003-2004 up to 2017-2018 years). Precautionary coverage was reevaluated on accordance to the form No. 5 of the state statistic observe data.

During the research period precautionary coverage from influenza has raised from $17.1 \%$ of communities in the 2003-2004 seasons up to 45\% in 2017-2018 years.

Correlation rate was calculated with non-parametric correlation rate of Spirman's degrees, and it is equal to 0.67 in the current research. To estimate the zero-hypothesis the target value of the criteria should be compared with the tabled value criteria. According to the Spirman's table of crucial correlation criteria $\mathrm{n}=15$ and along with the rate of statistic value 0.05 the crucial point for $\rho$ was 0.521 . Target value $(0.67)$ is more than crucial, discovered association between the precautionary coverage of influenza prevention and virulence is statistically valued. In addition, the correlation coefficient value and sign with which it turned out, we can suggest about the strength and direction of the connection.

This correlation coefficient is equal to +0.67 , that indicates a direct and average dependence, on this basis, it is proved, that there is an increase in vaccination coverage against influenza groups at risk (children over 6 months, people suffering from chronic diseases, pregnant women, as well as persons from occupational risk groups - health workers, teachers, students, service and transport workers) leads to a decrease in the incidence of this infection, prevent complications and reduce the number of deaths.

\subsection{5 doi: 10.15789/2220-7619-2018-4-1.15 \\ EPIDEMIOLOGICAL CHARACTERISTICS OF INCIDENCE OF CHRONIC VIRAL HEPATITIS B INFECTION AMONG HEALTHCARE WORKERS IN ST. PETERSBURG IN 2013-2017}

D.V. Vasilyev ${ }^{1,2}$, L.N. Pozhidaeva ${ }^{2}$, G.V. Chugunova ${ }^{3}$, L.V. Lyalina ${ }^{1}$

${ }^{1}$ St. Petersburg Pasteur Institute, St. Petersburg, Russia; ${ }^{2}$ Centre of Hygiene and Epidemiology in St. Petersburg, St. Petersburg, Russia ${ }^{3}$ Federal Service for Surveillance on Consumers' Rights Protection and Human Wellbeing, St. Petersburg, Russia

The aim of the study was to determine the clinical and epidemiological features of viral hepatitis B (HBV) in medical personnel newly identified in St. Petersburg under the conditions of vaccine prevention.

In St. Petersburg vaccination of health care workers began in 1996. Coverage with 3 -fold of hepatitis B vaccine among medical workers are expressed in the following figures: in $2013-94.7 \%$, in $2014-96.7 \%$, in $2015-96 \%$, in $2016-96.6 \%$, in $2017-96.7 \%$.

160 registered cases of viral hepatitis B in healthcare organizations in St. Petersburg, including 141 cases of chronic HBV, 5 cases of acute HBV, and 14 cases of HBV carriage. Out of 160 cases, 112 cases were medical workers $112(70 \%)$ and $48(30 \%)$ were not medical staff.

The incidence rate of HBV per 100000 medical workers was 38.2 in 2013; 50.8 in 2014; 24.3 in 2015; 22.7 in 2016; and 4.5 in 2017.

The group of medical workers consists of 99 cases of chronic HBV (88.4\%), two cases of acute HBV (1.8\%) and 11 cases of $\mathrm{HBV}$ carriage $(9.82 \%)(\mathrm{P}<0.05)$

Women predominate with $74.1 \%$ of cases while men comprise $25.9 \%(\mathrm{P}<0.05)$.

Age structure: $20-24$ years $-2.7 \%, 25-29$ years $-7.1 \%$, $30-34$ years $-7.1 \%, 35-39$ years $-5.4 \%, 40-44$ years $8.9 \%, 45-49$ years $-9.8 \%, 50-54$ years $-10.7 \%, 55-$ 59 years $-20.6 \%$, and from 60 and over $-27.7 \%$.

In the socio-occupational structure of $\mathrm{HBV}$ cases in 2013-2017, the main share is occupied by the middle medical personnel $-42 \%$, professional medical personnel $-33 \%$ and junior medical personnel $-25 \%$. The socio-occupational risk groups for HBV according to the type of departments are: surgical $-23.2 \%$, outpatient polyclinic $-17 \%$, dental $-8 \%$, therapeutic $-6 \%$, staff of clinical diagnostic and biochemical laboratories $-5.4 \%$.

Thus, the incidence of HBV in St. Petersburg in the conditions of vaccine-preventive maintenance of infection tends to decrease, over the five-year span by 8.5 times - from 38.2 in 2013 to 4.5 in 2017. The preponderance of persons over 55 years old among healthcare workers affected by HBV old and the dominance of chronic 